УДК 582.475.4.630*182:581.321.2

\author{
В. П. Коба
}

Никитский ботанический сад - Нацииональный научный изентр

\title{
МОНИТОРИНГ ХРОМОСОМНЫХ АБЕРРАЦИЙ В ПРИРОДНЫХ ПОПУЛЯЦИЯХ PINUS PALLASIANA
}

\begin{abstract}
Приведены результаты мониторинговых исследований хромосомных нарушений на стадии прохождения анафазы-телофазы. Дана статистическая характеристика динамики хромосомных аберраций по высотным поясам в популяциях Pinus pallasiana D. Don Горного Крыма. На южном макросклоне Главной гряды Крымских гор в древостоях $P$. pallasiana частота хромосомных аберраций в нижнем поясе выше по сравнению со средним и верхним поясами. Значительная изменчивость данного показателя по годам указывает на эпизодичность проявления факторов, влияющих на уровень хромосомных нарушений.
\end{abstract}

\author{
В. П. Коба
}

Нікітський ботанічний сад - Наџіональний науковий центтр

\section{МОНТТОРИНГ ХРОМОСОМНИХ АБЕРАЦІЙ У ПРИРОДНИХ ПОПУЛЯЦІЯХ РINUS PALLASIANA}

Наведено результати моніторингових досліджень хромосомних порушень на стадії проходження анафази-телофази. Надано статистичну характеристику динаміки хромосомних аберацій по висотних поясах у популяціях Pinus pallasiana D. Don Гірського Криму. На південному макросхилі Головного пасма Кримських гір у деревостанах $P$. pallasiana у нижньому поясі кількість хромосомних аберацій вища порівняно із середнім і верхнім поясами. Значна мінливість даного показника за роками вказує на епізодичність дії чинників, що впливають на рівень хромосомних порушень.

$$
\begin{gathered}
\text { V. P. Koba } \\
\text { Nikitsky Botanical Garden-National Scientific Center } \\
\text { MONITORING OF CHROMOSOMAL ABERRATIONS } \\
\text { IN NATURAL POPULATIONS OF PINUS PALLASIANA }
\end{gathered}
$$

This paper presents the results of monitoring research of the chromosome aberrations at the stage of anaphase-telophase. The statistical characteristics of dynamics of chromosomal aberrations in populations of Pinus pallasiana D. Don across the high-altitude zones of the Mountain Crimea is given. It is established that on the southern macroslope of the Crimean Main Ridge the frequency of chromosomal aberrations in the $P$. pallasiana stands is higher in the lower zone in comparison with the middle and upper zones. Significant variability of that parameter indicates the occasional effect of the factors influencing the level of chromosomal abnormalities.

\section{Введение}

При проведении эколого-генетического мониторинга большое значение имеет выбор тест-объекта, состояние которого наиболее адекватно отражает уровень действия и динамику анализируемых явлений. Оценку тех или иных тенденций изменения биологи- 
ческих характеристик тест-объекта традиционно осуществляют посредством сравнения с контролем, предполагая, что контрольный объект находится в условиях минимального или полностью исключающих негативное действие изучаемых факторов.

К сожалению, в настоящее время в связи с глобальными изменениями природной среды выделение контрольных объектов, их использование при оценке динамики экологических характеристик все более осложняется тотальным техногенным воздействием. Особенно в этом плане выделяется проблема химического и радиоактивного загрязнения, которому в последние десятилетия были подвержены обширные территории как в нашей стране, так и в других европейских государствах $[9 ; 11 ; 13]$. Сегодня даже в условиях заповедных территорий практически невозможно найти участки, которые не были бы подвержены глобальному техногенному воздействию [13]. Поэтому все большее значение приобретают мониторинговые исследования, позволяющие на основе хронологического анализа выделять те или иные изменения экологической ситуации, оценивать причинно-следственную связь и прогнозировать последствия антропогенного воздействия на природные объекты $[6 ; 11 ; 14 ; 15]$.

Цитогенетические методы широко применяются при оценке влияния неблагоприятных факторов на природные экосистемы $[4 ; 7 ; 9]$. В качестве индикаторов экологической нагрузки часто используют древесные растения [5; 10], среди которых хвойные считаются наиболее чувствительными к техногенному загрязнению [2; 6].

В Украине естественные древостои $P$. pallasiana расположены в горной части Крыма на территории двух заповедников: Крымского и Ялтинского природного горнолесного. Здесь они формируют практически единый массив площадью около 6 тыс. га. Это один из немногих в Украине и в целом в Европе участков сосновых лесов, который наименее всего как в прошлом, так и сегодня подвержен антропогенному воздействию. Поэтому результаты мониторинговых исследований хромосомных аберраций в древостоях $P$. pallasiana на территории данного массива позволяют дать характеристику не только текущего уровня мутационных процессов в природных популяциях в региональном масштабе, они также могут быть использованы при формировании информационной базы в системе общей оценки динамики фоновых показателей в связи с глобальными изменениями природной среды.

\section{Материал и методы исследований}

Материал для изучения хромосомных аберраций заготавливали в зоне естественного произрастания P. pallasiana. Пробные площади размером 0,20 га заложены по трем гипсометрическим профилям в восточной (район пос. Никита, площади № 1-3), центральной (район хребта Иограф, площади № 4-8) и западной (район пос. Алупка, площади № 9-11) части наиболее крупного массива ее лесов на южном макросклоне Главной гряды Крымских гор, простирающегося от пос. Запрудное до Симеиза (рис.).

Пробные площади охватывают перепад высот от 400 до 1200 м над уровнем моря. Закладку пробных площадей и выделение модельных деревьев (по 10 на каждой пробной площади) проводили с использованием общепринятых в лесоводстве и геоботанике методик [1;3]. С каждого модельного дерева в осенний период собирали 3040 шишек. Семена из шишек извлекали после их сушки в термостате при температуре $+45{ }^{\circ} \mathrm{C}$. Сравнительную характеристику хромосомных аберраций проводили при изучении делящихся клеток корневой меристемы проростков семян.

Полученные образцы материала фиксировали в уксусном алкоголе. Перед проведением наблюдений ткани корешков промывали в 70 \% этиловом спирте и проводили мацерацию в $3 \mathrm{H} \mathrm{HCl}$ в течение 45 минут при комнатной температуре. Меристему 
окрашивали ацето-железо-гематоксилином по методу Е. Г. Шоферистовой [12]. Анализ и учет хромосомных нарушений поводили, используя микроскоп «Биолам-И» в 10 полях зрения по каждому препарату. На стадии прохождения анафазы-телофазы учитывали следующие аномалии: образование одиночных и множественных мостов, фрагменты, опережение и отставание хромосом. Количественные результаты наблюдений обрабатывали, используя методы вариационной статистики [8].

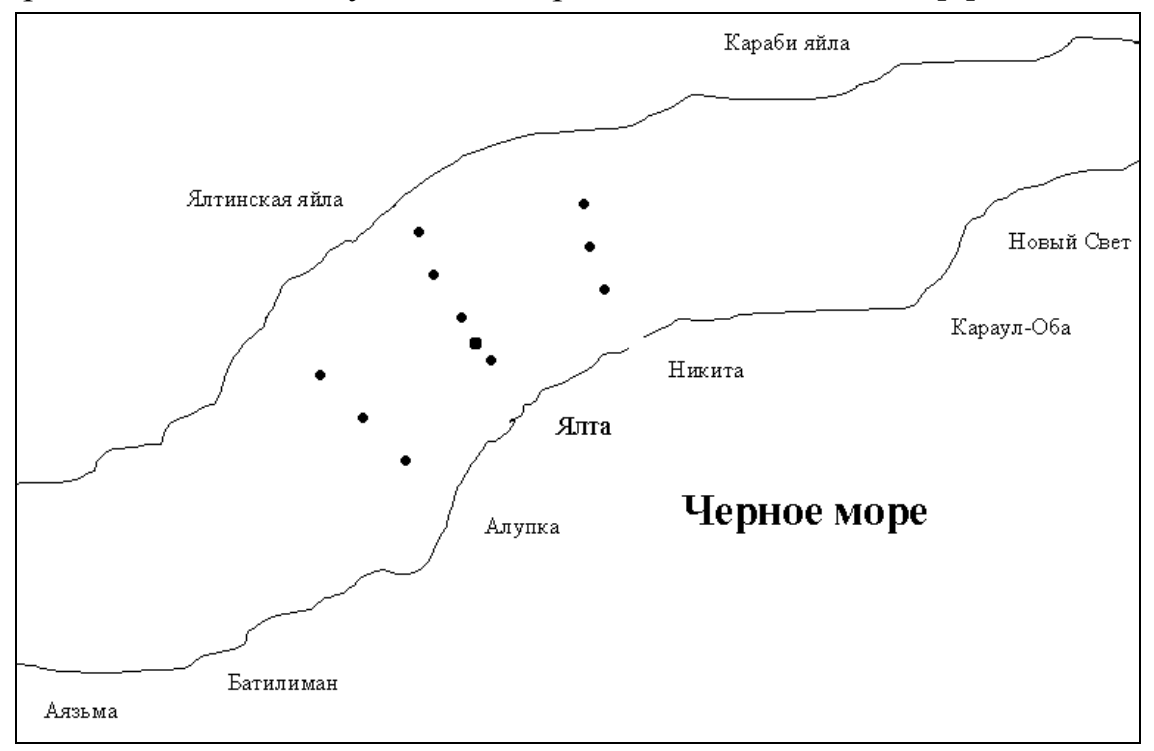

Рис. Схема расположения пробных площадей мониторинга хромосомных аберраций в популяциях Pinus pallasiana на южном макросклоне Главной гряды Крымских гор

\section{Результаты и их обсуждение}

Статистический учет хромосомных аберраций показал более высокую частоту их встречаемости в древостоях нижнего пояса (на высоте 400 м над уровнем моря). На пробной площади № 1 в 2004 г. количество клеток с хромосомными нарушениями составило 7,2 \% от общего количества делящихся клеток на стадии анафаза-телофаза (табл.). В 2007 г. этот показатель был заметно ниже (4,5 \%), что указывает на эпизодичность проявления факторов, влияющих на уровень хромосомных нарушений.

Более стабильный и повышенный уровень хромосомных аберраций в целом отмечается по центральному профилю. Здесь в 2004 г. на пробной площади № 4 отмечено 5,3 \% клеток с хромосомными нарушениями, в 2007 г. - 6,2 \%. Минимальное количество хромосомных перестроек для насаждений нижнего пояса наблюдалось в западной части исследуемого массива на пробной площади № 9: количество аномалий на стадии анафаза-телофаза составило в 2004 г. $-4,3 \%$, в 2007 г. $-2,8 \%$.

В среднем поясе процент хромосомных перестроек по всем трем профилям имеет примерно одинаковые значения и изменяется в пределах $3,1-4,2 \%$. В верхнем поясе, за исключением восточного профиля (пробная площадь № 3), количество хромосомных нарушений было также невелико.

Одной из причин повышения частоты хромосомных аберраций в нижнем поясе может являться более высокая степень подверженности этой зоны воздействию атмосферных загрязнений, поступающих сюда из урбанизированных территорий. Повышенная частота встречаемости хромосомных аномалий в митотически делящихся клетках ткани меристемы проростков семян из древостоев центрального профиля наи- 
более вероятно связана с тем, что они расположены в центральной части Ялтинского амфитеатра, где более существенно влияние городских источников загрязнения атмосферы. Этим также определяются здесь стабильно высокие показатели хромосомных нарушений по годам. Более того, по центральному профилю выявлена достаточно сильная связь изменения количества аберраций в связи с высотой произрастания древостоев над уровнем моря. В пределах высот 400-900 м коэффициент корреляции частоты проявления хромосомных перестроек с изменением высоты расположения пробных площадей в 2004 г. составил $-0,805$, в 2007 г. $--0,813$ (коэффициенты корреляции по $t$-критерию Стьюдента достоверны с 5 \% уровнем значимости), то есть с увеличением высоты над уровнем моря количество хромосомных нарушений уменьшается. По западному и восточному профилям такой связи не наблюдается.

Хромосомные аберрации в клетках меристемы проростков семян Pinus pallasiana

\begin{tabular}{|c|c|c|c|c|c|c|c|}
\hline \multirow{3}{*}{$\begin{array}{c}\text { № } \\
\text { пробной } \\
\text { площади }\end{array}$} & \multirow{3}{*}{$\begin{array}{c}\text { Высота } \\
\text { над ур. м., } \\
\text { м }\end{array}$} & \multicolumn{3}{|c|}{2004 г. } & \multicolumn{3}{|c|}{2007 г. } \\
\hline & & \multirow{2}{*}{$\begin{array}{c}\text { число про- } \\
\text { смотренных } \\
\text { клеток }\end{array}$} & \multicolumn{2}{|c|}{$\begin{array}{c}\text { ана-телофазы } \\
\text { с перестройками }\end{array}$} & \multirow{2}{*}{$\begin{array}{c}\text { число про- } \\
\text { смотренных } \\
\text { клеток }\end{array}$} & \multicolumn{2}{|c|}{$\begin{array}{c}\text { ана-телофазы } \\
\text { с перестройками }\end{array}$} \\
\hline & & & число & $\%$ & & число & $\%$ \\
\hline 1 & 400 & 2180 & 157 & $7,2 \pm 0,6$ & 1943 & 87 & $4,5 \pm 0,6$ \\
\hline 2 & 600 & 2294 & 97 & $4,3 \pm 0,4$ & 1856 & 67 & $3,6 \pm 0,4$ \\
\hline 3 & 900 & 2218 & 111 & $5,0 \pm 0,5$ & 2147 & 110 & $5,1 \pm 0,5$ \\
\hline 4 & 400 & 2092 & 109 & $5,3 \pm 0,6$ & 2063 & 128 & $6,2 \pm 0,6$ \\
\hline 5 & 500 & 2123 & 89 & $4,2 \pm 0,5$ & 2138 & 90 & $4,2 \pm 0,5$ \\
\hline 6 & 600 & 1983 & 81 & $4,1 \pm 0,4$ & 1978 & 75 & $3,8 \pm 0,4$ \\
\hline 7 & 900 & 2026 & 71 & $3,5 \pm 0,4$ & 1993 & 78 & $3,3 \pm 0,3$ \\
\hline 8 & 1200 & 2088 & 75 & $3,6 \pm 0,4$ & 2007 & 84 & $4,2 \pm 0,5$ \\
\hline 9 & 400 & 2250 & 97 & $4,3 \pm 0,5$ & 2144 & 60 & $2,8 \pm 0,3$ \\
\hline 10 & 600 & 2143 & 66 & $3,1 \pm 0,4$ & 2003 & 62 & $3,1 \pm 0,3$ \\
\hline 11 & 900 & 2087 & 71 & $3,4 \pm 0,3$ & 2116 & 51 & $2,4 \pm 0,3$ \\
\hline
\end{tabular}

Хотя западный и восточный профили находятся примерно на одинаковом расстоянии от центральной части Ялтинского амфитеатра и, соответственно, от главных местных источников атмосферного загрязнения, однако преобладающие в течение года юго-западные ветры [13] сносят основную массу загрязнителей в восточные районы массива лесов P. pallasiana на южном макросклоне Главной гряды Крымских гор. Это определяет повышенную частоту хромосомных нарушений в меристеме проростков семян из древостоев восточного профиля, а также значительную изменчивость данного показателя по годам, особенно в нижнем и среднем поясах, что, очевидно, связано с сезонной динамикой перемещения воздушных масс.

Необходимо также отметить, что наряду с количественными показателями в нижнем поясе (по сравнению с верхним и средним) существенно проявляются и качественные различия в характеристике хромосомных нарушений. В нижнем поясе чаще встречаются такие аберрации как одиночные и множественные мосты. Так, по центральному профилю в 2004 г. на пробной площади № 4 процент одиночных мостов от общего количества нарушений был в 2,8 раза больше, чем на пробной площади № 7, в 2007 г. это отношение снизилось до 1,4. По восточному профилю одиночных мостов на пробной площади нижнего пояса № 1 в 2004 г. было в 1,6 раза больше, чем на пробной площади верхнего пояса № 3. В 2007 г. этот показатель был равен 1,2. Хотя по западному профилю данные различия менее выражены, подобные изменения в качественном составе типов перестроек свидетельствуют о более глубоких хромосомных нару- 
шениях, имеющих место в популяциях $P$. pallasiana нижнего пояса на южном макросклоне Главной гряды Крымских гор.

\section{Выводы}

На южном макросклоне Главной гряды Крымских гор в древостоях P. pallasiana частота хромосомных аберраций в нижнем поясе выше по сравнению со средним и верхним поясами. Значительная изменчивость данного показателя по годам указывает на эпизодичность проявления факторов, влияющих на уровень хромосомных нарушений. Стабильно повышенное количество хромосомных аномалий в целом отмечается в центральной части изучаемого массива лесов P. pallasiana, что, очевидно, связано с более высокой подверженностью этой зоны воздействию атмосферных загрязнителей, поступающих сюда из урбанизированных территорий. В региональном масштабе выявлены тенденции увеличения хромосомных аберраций в природных популяциях $P$. pallasiana в связи с дальним переносом атмосферных загрязнителей.

\section{Библиографические ссылки}

1. Анучин Н. П. Лесная таксация. - М. : Лесная пром-сть, 1982. - 512 с.

2. Бахтиярова Р. М. Генетическая изменчивость сосны обыкновенной (Pinus sylvestris L.) в условиях промышленного загрязнения на Южном Урале. Сравнительное изучение групп деревьев различных категорий жизненного состояния / Р. М. Бахтиярова, Ю. А. Янбаев // Генетика. - 1996. - Т. 32, № 8. - С. 1135-1141.

3. Воробьев Д. В. Методика лесотипологических исследований. - К. : Урожай, 1967. - 388 с.

4. Гилева Э. А. Хромосомная нестабильность и содержание тяжелых металлов у амфибий из Юганского заповедника / Э. А. Гилева, Е. Л. Щупак // Экология. - 2005. - № 1. - С. 73-76.

5. Гродзинский Д. М. Радиобиология растений. - К. : Наук. думка, 1989. - 384 с.

6. Калашник Н. А. Хромосомные нарушения как индикатор оценки степени техногенного воздействия на хвойные насаждения // Экология. - 2008. - № 4. - С. 276-286.

7. Ковалева О. А. Цитогенетические аномалии в соматических клетках млекопитающих // Цитология и генетика. - 2008. - Вып. 42, № 1. - С. 58-72.

8. Лакин Г. Ф. Биометрия. - М. : Высшая школа, 1990. - 352 с.

9. Офицеров М. В. Генетические последствия радиационного воздействия на популяцию сосны обыкновенной (Pinus sylvestris L.) / М. В. Офицеров, Е. В. Игонина // Генетика. - 2009. - Т. 45, № 2. - C. 209-214.

10. Самошкин Е. Н. Воздействие химических мутагенов на древесные растения. - М. : Лесн. пром-сть, 1980. - 88 с.

11. Скок А. В. Воздействие хронического ионизирующего излучения на митотическую активность и хромосомные аберрации сосны обыкновенной в Южном Нечерноземье РФ / А. В. Скок, И. Н. Глазун, Е. Н. Самошкин // Вестн. Моск. гос. ун-та леса - Лесной вестник. 2011. - № 3. - С. 58-61.

12. Шоферистова Е. Г. К методике окраски хромосом и пыльцы // Ботанический журнал. 1973. - Т. 58, № 7. - С. 1011-1012.

13. Щербатюк Л. К. Методические рекомендации по контролю загрязнения атмосферы соединениями среды и прогнозу нарушений лесных экосистем // Никит. бот. сад. - Ялта, 1987. - 23 с.

14. All toxicity mechanism in tolerant and sensitive rye genotypes / S. Silva, C. Santos, M. Matos, O. Pinto-Carnide // Environmental and Experimental Botany. - 2012. - Vol. 75. - P. 89-97.

15. Kuchma O. Mutation rates in Scots pine (Pinus sylvestris L.) from the Chernobyl exclusion zone evaluated with amplified fragment-length polymorphisms (AFLPs) and microsatellite markers / O. Kuchma, B. Vornam, R. Finkeldey // Mutation Research / Genetic Toxicology and Environmental Mutagenesis. - 2011. - Vol. 725, N 9. - P. 29-35.

Надійшла до редколегії 25.02.2012 